\title{
INTRODUCTIION
}

\section{Restoring the Balance}

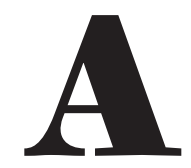

t some point in the first half of the twentieth century, Sigizmund Krzhizhanovsky (1887-1950) — a writer who, at the height of Stalinist repression, had not abandoned the arguably suicidal project of seeing his work into print - wrote a prospectus for a History of Unwritten Literature. Its opening lines identify the "biological cause" of unwritten literature: the closer an author approaches to death, the greater his accumulated literary to-do list. "As the quantity of themes and materials increases, life decreases in proportion." Worse yet, the growth of unused inspirations is exponential, since, according to Krzhizhanovsky's "law of unrealization," each idea ramifies into new ones until it has been finalized in writing. Thus the lengthier its period of gestation, "the more themes to which it gives birth," each demanding its own embodiment.

The proposed History might seem an effort on the part of a penniless holdover from the pre-Revolutionary period to discover a topic so inherently apolitical that it might possibly make its way through Soviet censorship. But Krzhizhanovsky's project also yields profound insight into the gap between intent 
and accomplishment, the archive and the canon. Although fundamentally impossible - "to what degree is research into the unrealized realizable?” Krzhizhanovsky asks — the project radically reorients literary culture upon the obligation to pay "some part of that thematic and narrative debt that previous generations did not liquidate" by taking on and carrying out their uncompleted projects. Far from a romantic or modernist quest for originality, writing appears as a kind of ancestor cult whose adherents, the aspiring authors of the present day, endeavor perpetually to perform their fealty to the past.

Despite the isolation and obscurity in which its author labored, Krzhizhanovsky's idea is of a piece with the wider literary culture of its time. American fantasist James Branch Cabell's Beyond Life, a 1919 collection of dialogues on aesthetics, takes place in a library containing "the cream of the unwritten books - the masterpieces that were planned and never carried out." In other ways Krzhizhanovsky's prospectus seems to prefigure the literary future. The very form in which it has come down to us - an idea for a book that fills in for the book itself-anticipates Stanisław Lem's collections of introductions to imaginary works, one of which describes a computer that completes unfinished literary monuments by Franz Kafka and Fyodor Dostoevsky. ${ }^{2}$

These examples illustrate the crux of Krzhizhanovsky's brief, long-unpublished prospectus for his History of Unwritten Literature: no matter how long a fragment of an idea persists in darkness, it must find visible form and spark new ideas in an audience beyond the purview of the author. Superficially, the sentiment resembles the famous line from Mikhail Bulgakov's 
Master and Margarita, also written at the height of the Stalinist terror and published decades later: "Manuscripts don't burn."3 But where Bulgakov's dictum is embedded in a religious allegory that links the persistence of the word and the hope for resurrection, the power that sustains Krzhizhanovsky's unpublished themes is an uncanny haunting by a ghostly potentiality-a humanist and secular version of Romantic notions of inspiration as a demonic or divine possession. The readers of subsequent generations, their brains now inhabited by the disembodied thought of a deceased person, cannot but transmit that thought to paper as it seeds their minds with new words.

Krzhizhanovsky's History offers an apt metaphor for his sprawling and inchoate legacy: a body of text that, as with other "rediscovered" writers of the early Soviet period, found an audience only after the fall of the Soviet Union. At once unmistakably of its time and entirely new to contemporary readers, the work of these writers is a signal instance of the "off-modern," to use Svetlana Boym's phrase for the many "alternative genealogies and histories of modernity" whose possibility haunts and shadows modernity itself. Krzhizhanovsky's diagnosis of an inverse correlation between biological life and creative endeavor even makes a subtle political commentary: in the Stalinist context of censorship and mass persecution, the very survival of Soviet writers was intertwined with their literary pursuits. During Krzhizhanovsky's creative peak, the advancing totalitarianism of Soviet life turned aesthetics into politics and literary choices into matters of life or death. 
Judging from the fate of his better-known contemporaries, it might be argued that Krzhizhanovsky escaped the worst: he was neither shot like Isaak Babel, nor sent to die in the camps like Osip Mandelstam, nor publicly ostracized like Mikhail Zoshchenko. And yet against the background of the Stalinist night, his star shines with a particularly tragic quality. A prolific writer of spectacular talent and breadth of vision, Krzhizhanovsky was denied publication with such consistency that by the time of his rediscovery in the 1980s, he was almost completely forgotten. It is hard to say who comes off worsethe writer, whose prose was heard by only a small group of listeners; the readership, deprived of this prose for almost forty years after the writer's death; or the literary tradition itself, bereft of one of its most singularly original voices. If not for the brutality of its execution, the last decade of Krzhizhanovsky's life in particular, when he stopped writing almost entirely, could have easily appeared in one of his own fictions; for example, his masterpiece, The Letter Killers Club, in which a group of ex-authors bands together around a belief that putting words on paper brings death to the creative potential of the imagination.

Reading Krzhizhanovsky, one feels that his presence in Russian letters is something of an anomaly, the result of an unusual implant into the Russian soil. The effect of foreignness is partly explained by biography: he grew up in a Catholic Polish family on the outskirts of Kiev. (Polish came in handy during the last years of his life, when he earned his living translating Polish literature into Russian.) He moved to Moscow in 1922, close on the heels of his fellow Kievan Mikhail Bulgakov. 
Like Bulgakov, he was heavily invested in the bustling theatrical life of early Soviet Moscow and lived in his adopted city until his death. Soon after his arrival in the capital, Krzhizhanovsky began his long-standing association with Alexander Tairov and his Chamber Theater. One of the many fruits of that collaboration was the "Philosopheme of the Theater," a major essay on the potentiality of theater as an art form and category of human consciousness. In whatever genre he worked-and he worked in most of them-Krzhizhanovsky's prose often reads like a literary translation of a philosophical problem. In one of his few published fictional texts, the 1919 story "Jacobi and 'As If," ' German philosopher Friedrich Heinrich Jacobi earnestly discusses ontology with a personified subjunctive. Pitting the philosopher against a word that is almost but not quite identical with his name, the story's Russian title-“Якоби и якобы” ("Iakobi i iakoby") — gives a good indication of the problems awaiting Krzhizhanovsky's translators, not least his predilection for wordplay.

Krzhizhanovsky's most obvious legacy is in literary fiction. His first collection of stories and novellas, Stories for Wunderkinder, had been conceived back in Kiev and slated for publication in 1926, but the publisher went bankrupt before it could be printed. In 1941, another attempt to publish it was prevented by the paper shortage caused by the Nazi invasion of the Soviet Union. Several other collections of short fiction had been scotched by the censorship apparatus in the interim. In the forties, Krzhizhanovsky stopped writing fiction altogether, although he continued to channel his creativity into other genres, writing plays and philosophical excurses as well as a 
closely observed account of wartime Moscow. He drank heavily in his last years and suffered a series of strokes in 1949-50, which afflicted him with a form of aphasia called alexia, the inability to read. As a result, this master of wordplay spent the last months of his life struggling to relearn the Russian alphabet. On December 28, 1950, Krzhizhanovsky died.

The story of his revival, at the far end of the twentieth century, also might have come from his own hand. Vadim Perelmuter, a poet and scholar who was working on the archive of poet Georgii Shengeli almost thirty years after Krzhizhanovsky's death, discovered a private obituary in Shengeli's notebooks: "Today, on December 28th, 1950, Sigizmund Dominikovich Krzhizhanovsky, a science fiction writer and 'overlooked genius,' whose gifts were equal to those of Edgar Allan Poe and Alexander Grin, has died. Not a single one of his lines was published during his lifetime." ${ }^{5}$ The note's sensational promise led Perelmuter to the practically complete archive of a major modernist writer whose fiction remained virtually unknown: a researcher's fantasy and a reader's treasure trove. The author appears out of Lethe as the eyes of his first future reader fall on the note announcing the death of the man; one hopes that Krzhizhanovsky would have found the story amusing.

Shepherded out of oblivion by Perelmuter, Stories for Wunderkinder appeared at last in 1989. Its distinctive blend of metafictional paradox and philosophical fable immediately earned its author the sobriquet "the Russian Borges"-a fairly apt shorthand comparison, if one that places its author far outside his actual historical and national context. Other works soon followed, and Perelmuter's able stewardship of Krzhizhanovsky's 
legacy culminated in the amply annotated six-volume Collected Works, which represents not just his fiction but also his critical essays, dramas, aphorisms, and philosophical writings. The comparison to Borges testifies, once again, to the impression Krzhizhanovsky gives of a writer transplanted into Russian letters from another place and time, fundamentally alien to the vast social panoramas for which Russian fiction is best known internationally. Krzhizhanovsky's deep penetration into the materiality of the Russian language, most evident in his love of puns and proverbs, testifies to how well the foreign implant took. Nonetheless his most obvious literary influences come mostly from the West: Jonathan Swift, H. G. Wells, E. T. A. Hoffmann, Edgar Allan Poe, and Gustav Meyrink.

In his 1928 novella The Return of Munchausen, Krzhizhanovsky rewrites Rudolf Raspe's 1785 classic (one of his perennial points of reference) by bringing Munchausen back to Russia-this time to its Soviet iteration. The master of the tall tale is undone by the encounter, since Russia has become more absurd and unbelievable than Munchausen's imagination. Confronted with this "country about which one cannot lie," the baron is forced to admit that reality has exceeded his capability for invention. ${ }^{6}$ For insight into this fictional episode we can turn to Krzhizhanovsky's prospectus for another unwritten scholarlybook, a History of Hyperbole. This whirlwind rehearsal of exaggeration in world literature ends with the observation that in the Soviet 1930s, "the writer need only record realistically the pace of history, which has exceeded realism's customary orientation." Krzhizhanovsky here links his fantastic tales to the mainstream of Russian literature through the 
insight that modernization in Russia happened, in Marshall Berman's words, "in the most jagged, halting, blatantly abortive or weirdly distorted ways." 7 Berman finds these discordant scales of time to register in literature as the ghosts and doubles haunting the Petersburg tales of Pushkin, Gogol, and Dostoevsky. From this point of view we might see Krzhizhanovsky's apparent foreignness within Russian literature as a temporal as well as geographic dislocation. In his essay "A Collection of Seconds," Krzhizhanovsky defines early Soviet photographs as discombobulated "collections of seconds which have captured within them elements of old and new daily life"; in another feuilleton of the 1920s, Krzhizhanovsky describes the streets of revolutionary Moscow as a palimpsest of names, referring at times to the city's medieval past, at other times to its communist future, so that the city itself seems to exist in a temporal gap between the ruins of history and the mirage of a world to come. ${ }^{8}$ Obsessed with the burden of the past even as it dabbles in science fiction, Krzhizhanovsky's writing emerges from a similar gap between the nostalgic and the utopian, the no more and the not yet.

In both his fiction and nonfiction, Krzhizhanovsky points beyond the realist tradition to the Renaissance, Baroque, and Enlightenment periods that Russia scarcely knew. His phantasmagorical prose is deeply rooted in gothic romance and often gravitates toward allegory; among Krzhizhanovsky's Russian predecessors one must include Nikolai Gogol and Vladimir Odoevsky, who similarly wrote loosely framed collections of stories in the vein of early Romanticism. Krzhizhanovsky credits his fictional method, which he dubs 
"experimental realism," to his pre-realist precursors, William Shakespeare and Jonathan Swift. Its motive force comes from the conditional particle "as if" which allows the writer to transcribe what follows from the irruption of an idea-no matter how improbable-into life. As Krzhizhanovsky writes in his grand tour of the imaginary territories of fantastic literature, "Countries That Don't Exist," "It's interesting that only once in the first two parts of Gulliver's Travels did Swift, a true artist, allow himself to violate proportion - to shrink or enlarge the bodies of the people among whom his hero lived. Henceforth, he was extraordinarily precise and adhered to a strictly realistic style."

Krzhizhanovsky's prose, in which perspective and scale are altered without distorting human features or mental capacity, grafts only a single element of the fantastic onto an otherwise rigidly realistic base. He thereby complicates Tzvetan Todorov's definition of the fantastic as the tension between the uncanny and the supernatural. Although Krzhizhanovsky's philosophical parables and fantastic visions take place mostly in abstract locales drawn from literary convention more than observed reality, they hardly could have been conceived and nurtured anywhere apart from Soviet Russia-where, as the 1920 anthem "The March of the Aviators" has it, "the fairytale is meant to come true." To recall once more Munchausen's account of the Soviet Union, it was a country in which ideology permeated life to such an extreme degree that its absurd reality outstripped the literary imagination. 
In addition to more than a hundred short stories and novellas, Krzhizhanovsky's corpus contains a wide variety of genres that fit into the larger spectrum of belles lettres. His range and versatility are appreciable even in the small number of texts that saw the light of day during his lifetime, either in print or on stage: unattributed vignettes for the Chamber Theater's in-house weekly, a series of sketches about Moscow, a couple of critical essays - out of fourteen(!) — on Shakespeare, a few other essays (out of the more than fifty that he wrote) on the history and theory of literature and theater, an uncredited script for Yakov Protazanov's 1930 film St. Jorgen's Day, stage adaptations of Gilbert Keith Chesterton's The Man Who Was Thursday and Pushkin's Eugene Onegin (with music by Sergei Prokofiev), parts of a libretto for a patriotic opera written during World War II, and uncredited entries for the Great Soviet Encyclopedia. None of his plays and only six works of original fiction were published in his lifetime. ${ }^{9}$

Like Krzhizhanovsky's fictional texts, his critical and philosophical writings inhabit the borderland between poetic and speculative prose. In our selection for this volume, we have aimed to showcase Krzhizhanovsky's range as well as his originality. The reader will find the neo-Kantian philosophical essays of Krzhizhanovsky's late teens; the feuilletons and quirky essays of the 1920s; literary criticism from the 1930s, when he was struggling to secure his membership in the Writer's Union; the wartime notebooks of the 1940s; running meditations on the theater in genres ranging from manifesto to metaphysical dialogue; as well as the fragments, fables, aphorisms, and jotted ideas that span his entire career. Yet in the same breath with 
the diversity of Krzhizhanovsky's talent we can speak of the unity of his oeuvre. It is as if a major idea, a leitmotif, a method were migrating from one genre to another, presenting itself in different guises but always immediately recognizable. In all his writings Krzhizhanovsky stands out as the twentieth century's outstanding thinker of potentiality. His texts lament their own obscurity and often express an unverifiable belief in their destiny. "I am known for being unknown," he quips in one epigram; in another, "I am at odds with the present day, but eternity loves me."10 In addressing his lack of an audience, Krzhizhanovsky expresses both resignation regarding his historical circumstances and a seething ambition to speak beyond them: "I am not a man, but a sword. I will lie in my grave as in a scabbard."

A chaotic cornucopia of ideas populates Krzhizhanovsky's notebooks, few if any of them adequately realized and a number of them reiterating one another. His various manuscripts are written in observably different styles, genres, and settings, and yet they all evince the idée fixe of Krzhizhanovsky's entire oeuvre, which revolves around a fundamental paradox of creative language. How does an idea take shape in the artist's inner world, emerge into the external world as a material object, and lodge itself in the minds of others? Krzhizhanovsky's earliest essays, such as "Idea and Word," had already theorized the passages and permutations of the private and public word. The image of the writer's mental life as a blade seeking to sheathe itself in the brain of the reader, instantiated in the aforementioned aphorism, circulates through multiple texts and across genres. Over the years of his professional obscurity, the liminal 
status of Krzhizhanovsky's writings lends this image a metafictional function as well as a rich pathos. The metaphor dramatizes Krzhizhanovsky's hermetic creative life and the uncanny autonomous force of the unrealized idea; its persistence testifies to the frustration of a restless imagination that cannot find release in a readership. Even if his work had been condemned by its audience, publication in vitam might have created for Krzhizhanovsky an opening onto the world and the possibility of vitalizing dialogue.

The psychological effects of this creative isolation on Krzhizhanovsky's writing must have been profound, and not always for the good. His idiosyncratic style is occasionally awkward; unchecked wordplay sometimes overwhelms the intricate texture of the prose. His works are uneven in quality, even bearing in mind the different audiences for which he attempted to write. Krzhizhanovsky's exclusion from official literary production helps to account for these deficiencies, so long as we remember that it also provided the fertile ground where the author's creations could grow wild, earning him an exceptional place in Russian modernism. Perhaps more than any other Russian writer of the first half of the twentieth century, Krzhizhanovsky was conscious of the process of writing itself, which he envisioned as a conduit between the realms of idea and matter. His texts are true experiments (not a few of them failures), exploring scenarios in which the word becomes aware of its ability to bequeath physical existence upon ideas. For this reason, too, Krzhizhanovsky's fiction cannot be separated neatly from his activity in nonfiction genres. His efforts in 
his many literary modes can be seen as incarnations of a single swarm of restless ideas, restating themselves as poetry, fable, essay, aphorism, memoir, but always in images that resonate from one text to another and encode the same preoccupations.

The kinship between his fiction and his essays is not just thematic but formal. If his fiction enfolds numerous mises en abyme of the essayistic or prospective variety, his work in critical genres teems with verbal play. Take, for example, the essay "The Poetics of Titles." In it we find not just an appreciation for the title as a literary genre but a carefully patterned text that, in the original Russian, abounds in assonance, alliteration, and verbal meter. The initial thrust of the essay is motivated largely by a pun on the morpheme glav, or "head," which appears in both the word for title (zaglavie) and an idiom for "the most vital thing" (glavnoe). As Krzhizhanovsky leads us into his topic, our sense of what is central and what is ornamental - the most vital thing in the text and the paratextual appendage that adorns the cover-become fundamentally destabilized. The title in Krzhizhanovsky's conception both addresses the world without (enticing readers to buy the book) and speaks to the idea within (distilling its theme into a compact utterance), promising potentiality to the one and realization to the other.

The subject matter Krzhizhanovsky chooses in "The Poetics of Titles" is, moreover, part and parcel of his obsession with synecdoche. In this essay an appendage of the literary text comes to life as a pretext for Krzhizhanovsky's mental gymnastics and displays of erudition. The conceit is of a kind 
with the short story "The Runaway Fingers," in which a pianist's fingers scurry off the keyboard: the fantastic enters the text as the metonymy springs to life. Language's hybridity, as a material medium for abstract thought, underlies the particularly linguistic nature of Krzhizhanovsky's phantasmagoric prose. Not just titles but individual words and letters receive physicality; concepts become personified, idiomatic expressions literalized; parts achieve autonomy from the whole. This analytic poetics remains, however, in communication with the system-building philosophical tendency. In "The Poetics of Titles," the accumulation of examples evolves into a coherent theory of titles and a powerful commentary on the place of reading and writing — and, ultimately, art-within the quickening tempo of modern life, reminiscent of essays by Georg Simmel and Walter Benjamin.

The philosophical stakes of a poetics based in the physicality of language comes through most efficiently in "Philosopheme of the Theater," which defines its key concepts through a playful technique resembling parlor games such as ghosts or word golf. Krzhizhanovsky subtracts a suffix from бытие (bytie), the metaphysical concept of Being with a capital B, to arrive at быт (byt), meaning everyday life, humdrum existence, all that is taken for granted and passes without notice. Another subtraction takes him to the pure potentiality represented by the two-letter sequence бы $(b y)$, the conditional particle, which can mean "if" or "as if" and works as a marker of the hypothetical. For Krzhizhanovsky, this sequence illustrates the ceaseless dynamic through which material existence mediates potentiality on the one hand and transcendental 
concepts on the other. A philosophical ladder spanning unrealized and ideal existence, the bytie-byt-by series invites us to blur the boundaries between happy linguistic accident and phenomenological insight.

Krzhizhanovsky's linguistic cum philosophical play allows us to establish him as an intermediary between the two most influential poles of Russian literary modernism: symbolism and futurism. During the first decade of the twentieth century, symbolism was the dominant presence on the Russian literary and artistic scene. Drawing on mystical Christianity and idealist philosophy, symbolism presented a coherent philosophical and aesthetic system grounded in the existence of a transcendental world of forms (noumena) and an immanent world of matter (phenomena). The movement's influence is most directly felt in Krzhizhanovsky's early philosophical essays "Love as a Method of Cognition," "Idea and Word," and "Argo and Ergo," which share the premise of a distinction between those two worlds.

In "Love as a Method of Cognition," Krzhizhanovsky posits that transcendental truths can be apprehended only through love, the single force capable of forging our mystical unity with universal being. "Idea and Word" explores the difference between the internal word-the word of the "mind" or "soul" (dusha) — and its external manifestation as an "outside" (ulichnoe) word. It can be seen as a reflection on Fyodor Tiutchev's 1830 poem "Silentium," which in a famous line 
insists that "the spoken thought is a lie." "Argo and Ergo" is similarly preoccupied with the loss of potency that accompanies the shift from mystery to revelation. "All the things in my world I divide into these and Those," Krzhizhanovsky pronounces, making the hierarchy between the deficient world of phenomena and unattainable world of noumena clear through capitalization.

Unlike the symbolists, whose worldview assumes the static inviolability of this hierarchy, Krzhizhanovsky, even in these early efforts, finds purpose in the dramatic tension between its binary elements. His fiction and nonfiction alike can be read as a prolonged meditation on what we might term the dynamics of interpermeability between the two realms, which ultimately calls into question the ontological primacy of one over the other. Already in "Argo and Ergo" the "this-into-Thaters," who concern themselves with movement from the world of matter into the world of ideas, are balanced by "That-into-thisers," who reverse the direction. By the 1920 s we begin to see in Krzhizhanovsky's writing the collapse of the strict binary division between the two worlds. In "The Poetics of Titles," to take one example, the deductive method through which Krzhizhanovsky constructs an all-encompassing theory is offset by the similarly powerful inductive drive: the sheer variety of examples threatens to shatter the whole into disparate and eccentric fragments. We can perceive the same principle at work in Krzhizhanovsky's obsessive wordplay, which serves as an efficient device for conveying complex theoretical conceptions (the bytie-byt-by sequence and the title "Argo and Ergo" are 
just a few of the examples mentioned earlier) but which diverts our attention from the idea to the materiality of language.

Krzhizhanovsky's interest in the formal attributes of the word as a material medium, its flexibility and self-sufficiency, draws comparison with artists of the Russian avant-garde who saw their work as a radical break with the aesthetics of the symbolists. The poetic experiments of futurism treated language as material with which to construct new meanings, typically by breaking words down into patterned morphemic and phonetic particles. Transformation of poetic meaning through the addition and subtraction of letters was a staple of poets like Vasilii Kamenskii, whose 1914 poem "Я" ( $i a$, "I") operates according to a similar method:

$\begin{array}{ll}\text { Изиучистая } & \text { izluchistaia, "meandering," "sinuous" } \\ \text { Иучистая } & \text { luchistaia, "rayed" } \\ \text { Чистая } & \text { chistaia, "clean," "pure" } \\ \text { Истая } & \text { istaia, "genuine" } \\ \text { Стая } & \text { staia, "mob," "horde," "flock," or "pack" } \\ \text { Тая } & \text { taia, "melting," but also "hiding" } \\ \text { Ая } & \text { aia, adjectival suffix } \\ \text { Я } & \text { ia, "I" }\end{array}$

In this case, too, the sequence implies a meaningful narrative: the mob or flock melts away under the pure rays of the sun in order to reveal the hidden genuine speaking self of the individual poet, who triumphantly emerges from the cocoon of language and announces his presence in the last line. 
The futurists referred to their manipulations of language as zaum, a neologism derived from the morphemes meaning "beyond" and "mind, reason," often rendered into English through the equivalents "beyonsense" or "transrational." Zaum was to be a pure language of poetry, liberated from conventional meaning; exulting in phonetic, morphological, and syntactic ambiguity; verging in various manifestations on religious glossolalia, the sound play of infants, or the dream of universal language. Krzhizhanovsky nods to zaum directly in a scene in The Letter Killers Club in which a medieval monk composing chants deforms the words, "nonsensing [bessmyslia] the syllables for the sake of other abtruse [zaumnye] meanings." The creative deformation of language-breaking its words down into constituent parts and repatterning them for poetic effect-is not just represented in the monk's actions but also performed by Krzhizhanovsky's neologism "nonsensing." As the reader of Krzhizhanovsky rapidly becomes aware, his oeuvre boasts hundreds of neologisms. Writing about the impossibility of fitting original thoughts into the common currency of conventional language in "Idea and Word," Krzhizhanovsky resorts to "kaleidescoplets [kaleidoskopiki]" and "desensification [obessmyslivanie]," to name just a few of the fruits borne by the morphological resources of the Russian language.

To sense the constituent morphemes of words is, of course, a crucial expression of Krzhizhanovsky's poetics, which emphasizes the potential of synecdoche. In his critical essays he brings the same tactic to bear on literary history. "The Poetics of Titles" points out that the three major novels of nineteenth-century realist Ivan Goncharov represent 
a coherent series of elaborations on the Russian prefix $o b$, each more abbreviated than the last.

$$
\begin{aligned}
& y k n o v e n n a y a \text { istoriya (A Common Story, 1846) } \\
& \text { Ob- } \quad \text { lomov (Oblomov, } 1859 \text { [oblomat' means to "fail/break } \\
& \text { off."-Trans.]) } \\
& \text { ryv (The Precipice, 1869) }
\end{aligned}
$$

Like a mathematician presented with a set of numbers, Krzhizhanovsky predicts from this series a fourth book, which is to intensify the idea of a break or rupture.

Krzhizhanovsky's contention that the repeated prefix makes legible an underlying logic to the writer's career recalls a claim made by Velimir Khlebnikov, the most gifted and innovative poet of zaum: that the beginning of a word "governs the whole word-sets orders for the rest of it." ${ }^{12}$ In his notebooks and manifestoes Khlebnikov exhaustively catalogues the underlying meanings of letters and prefixes, apparently with the aim of devising "a new world language for the whole human family." In "Philosopheme of the Theater," the bytie-byt-by sequence is in fact built on a description of Leibniz's " 'globus intellectualis,' a closed sphere of symbolic signs that without the mediation of words expresses the whole system of essences in the universe." "The Poetics of Titles" ends with an almost identical paragraph, suggesting that titles, as shorthand signs for complex content, presage "the moment when the orbits of the earthly globe and the globus intellectualis will inescapably collide." The idea of a universal or Adamic language, in which being and word would fuse into one, seems to be the limit case of Krzhizhanovsky's idealism. 
The translingual aspirations of Krzhizhanovsky's wordplay shine through in his notebooks, which, among the titles for unwritten stories and aphoristic jottings, include multilingual puns in idioms including Polish, Italian, and English. Take this example:

Die $=$ die $:$

Игра в кости-умирать ["a game of dice (literally, 'playing at bones') is- to die" $]^{14}$

Here a simple sound coincidence in English motivates another equation between death and "playing at bones," now meaning to perform the role of a skeletal corpse as well as to throw dice. The commonplace Russian phrase is made strange and macabre through its triangulation with a simple English pun; the pun is lent profundity through its displacement into Russian. The joke is consistent with the association of games and death throughout Krzhizhanovsky's work-as in “The Dramaturgy of the Chessboard," which identifies both board games and works of art as "small conditional worlds" that distract the mind from life and absorb it in the dead end of a manmade puzzle (or, perhaps, trap).

Krzhizhanovsky's definition of the artwork as a "conditional [uslovnyi] world" unfolding according to the laws of literary convention, like his emphasis on the mystifying and defamiliarizing functions of verbal art, might be in dialogue with formalist theorist Viktor Shklovsky, whose influential theory of ostranenie - itself a quasi-futurist neologism meaning "enstranging" or "making strange"-was devised not least in 
order to justify and theorize Khlebnikov's poetry. In his most famous essay, the 1917 "Art as Device," Shklovsky writes that "by 'enstranging' objects and complicating form, art makes perception long and 'laborious." "15 Like Shklovsky, Krzhizhanovsky argues (in the 1918 "Argo and Ergo") that riddles are the primal form of "artistic creativity, an attempt to make the comprehensible incomprehensible." And yet Krzhizhanovsky expresses contempt for formalist efforts to assimilate literary studies into scientific inquiry by focusing on the measurable, material aspects of verbal art: "Nowadays That-into-thisers, who manage the business of art theory and criticism, teach us how to crack riddles, i.e., to unriddle them." Despite his affinity with the verbal innovation of futurist poetics and the formalist valorization of difficulty and the "rules of art," Krzhizhanovsky suggests that in cutting themselves off from the transcendental concept whose mystery cannot be reduced to its material manifestation, his peers in the avant-garde are missing the point.

In fact Krzhizhanovsky is interested in linguistic innovation less for its own sake than for its ability to test the complex role that language plays in human life and in the life of the idea, both of which he endows with subjecthood and agency. To enter into communion with others, ideas must find their entrance into life, into language - and Krzhizhanovsky, in what perhaps most betrays his belonging to Russian culture, almost ubiquitously describes this journey as traumatic. One of the most common metaphors in his prose involves a crack between the two worlds, an absence whose emblem is the creative fissure in a fountain pen's nib splitting the white of the page with black ink. Yet only ideas can breathe life into dead matter: in 
"Idea and Word," Krzhizhanovsky writes of words as skulls, empty forms requiring thought to be reanimated. As the word takes on a life of its own, it splinters the mind, depriving the creative subject of wholeness and autonomy. By demanding an audience, even an interlocutor, writing sets up an ethics. Writing is a boundary that separates the pure forms of thought from material existence. It calls for accountability and responsibility even as it guarantees radical loneliness. For Krzhizhanovsky, a man who devoted his life to writing unread pages, literature is at once a bridge into the lives of others and the precipice that reinforces the divisions between us.

As noted earlier, Krzhizhanovsky's literary themes readily resonate with the most dramatic moments and poignant tendencies of his own life. In forging his biography, Krzhizhanovsky seems to follow the impulse of zhiznetvorchestvo, or "life creation"-a doctrine that aimed to collapse the boundary between life and art and guided the projects of the Russian symbolists, with many of whom Krzhizhanovsky was close. Yet the ideal of zhiznetvorchestvo hardly accounted for the state's ideological intrusion into creative pursuits. Krzhizhanovsky's more fundamental affinity with symbolism resides in his efforts to stage the life cycle of the idea, from the full potentiality of its transcendental form to its actualization in the material world, where, as if soiled by matter, it loses in purity but acquires political and ethical significance. In writing - in any artistic undertaking, really-ideas give up their transcendental 
quality and take on material forms. It is only in this degraded condition that thought is able to venture forth into the alien embodied reality of existent things and leave its mark. At the same time, writing restores the balance, generating new ideas in new minds, thereby transcending the material word and returning to the potentiality of the ideal. As the protagonist of Krzhizhanovsky's story "Someone Else's Theme” points out, the etymology of the Greek word talent ( $\tau \dot{\alpha} \lambda \alpha v \tau o v$ ) is "scale" or "balance," and artistic labor becomes the fulfillment of a duty toward life-or, as he puts it, the repayment of "the bill presented by the sun." 16

Here Krzhizhanovsky writes himself into an ancient mystical tradition that imagines God as an inexhaustible creditor whose loan we must unceasingly pay back. Krzhizhanovsky's time on earth, which he devoted to writings that he would not see reach a public, can be seen as an ascetic quest to settle accounts with life. The following pages are partial payment toward an infinite debt.

\section{Jacob Emery and Alexander Spektor}



COUNTRIES THAT DON'T EXIST' 
